\title{
Effect of fiber-reinforced composite at the interface on bonding of resin core system to dentin
}

\author{
Isil CEKIC-NAGAS ${ }^{1}$, Gulfem ERGUN¹, Arzu TEZVERGIL², Pekka K. VALLITTU² and Lippo V. J. LASSILA² \\ ${ }^{1}$ Department of Prosthodontics, Faculty of Dentistry, Gazi University, Ankara, Turkey \\ ${ }^{2}$ Department of Prosthetic Dentistry and Biomaterials Science, Institute of Dentistry, University of Turku, Turku, Finland \\ Corresponding author, Gulfem ERGUN; E-mail: ergungulfem@yahoo.com, isilcekic@gmail.com
}

\begin{abstract}
The aim of this study was to evaluate the effect of fiber-reinforced composite (FRC) at the interface on bonding of resin core systems to bovine dentin using different adhesive systems. To this end, the labial surfaces of 60 bovine incisors were ground to obtain flat dentin surfaces and then divided into two groups according to the adhesive system used: total-etching (Solobond Plus) versus self-etching (Clearfil SE Bond). Resin core systems were bonded to tooth structure either without or with a FRC layer (everStick Net, StickTech). For groups with FRC layer, a silicon forming aid was used to adapt the latter on the dentin surfaces. After resin core was polymerized with Optilux 501 for 40 seconds, the specimens were tested in a universal testing machine. ANOVA revealed that presence of FRC at the interface had a significantly positive effect on bond strength $(p<0.001)$. However, differences between groups were not significant for either adhesive system ( $p=0.076)$ or with the use of silicon forming aid $(\mathrm{p}=0.348)$.
\end{abstract}

Key words: Bond strength, FRC, Silicon device

Received Jan 17, 2008: Accepted Apr 30, 2008

\section{INTRODUCTION}

The outcome of endodontic treatment for all patients should be high levels of comfort, function, and longevity. On this note, preservation of the remaining tooth structure is instrumental to augmenting the longevity of restored teeth ${ }^{1)}$. On the techniques available to preserve sound tooth structure, core foundation systems are frequently used to repair endodontically treated teeth after excessive loss of the coronal portion and to stabilize the weakened parts of tooth structure ${ }^{2}$. Further, to combine the advantages of chemical- and lightpolymerized materials so as to improve the dentin bond strengths of direct core foundation systems, dual-polymerized core foundation resins were developed ${ }^{33}$.

Key to the success of tooth restoration treatments are an appropriate adhesive system and core foundation system ${ }^{4}$. Current adhesive systems interact with dentin using two different strategies: remove the smear layer (total-etch technique) or maintain it as the substrate for bonding (self-etch technique $)^{5}$. The introduction of self-etching adhesives has since eliminated the use of separate acid-etching step and significantly reduced postoperative sensitivity associated with the removal of smear layer ${ }^{6}$. For two-step self-etch adhesives, they require separate application steps of a mild self-etch primer and a hydrophobic resin. These mild self-etch systems $(\mathrm{pH}<2)$ are able to partially remove the smear layer and penetrate the dentin surface, creating a less pronounced resin tag formation and hybrid layers that are thinner than those of totaletch systems ${ }^{7}$.

Adhesion to dentin substrate provides retention for the core foundation resin as well as reinforcement characteristics that are beneficial in the treatment of compromised teeth ${ }^{8}$. In view of the significant impact of interfacial adhesion on the mechanical properties and long-term durability of foundation restorations, it is therefore needful to establish appropriate methods to assess changes in the strength and stability of the interface ${ }^{9)}$. Indeed, bond failures at dentin-resin composite interface have been shown to occur due to cohesive fracture within the resin composite-bonding agent complex in the presence of concentrated stress at the interface ${ }^{10)}$. Therefore, to increase bond strength, there must be means and measures to reduce or eliminate stress concentration at the interface ${ }^{10,11)}$.

One available method is to use fiber-reinforced composites (FRCs) at the interface ${ }^{10,12)}$. It should be mentioned that orientation of the fibers is an important factor that affects the strength of $\mathrm{FRCs}^{133}$. Unidirectional fibers provide reinforcement only in one direction and confer anisotropic properties to the composite resins. When fibers are oriented in two or three directions, they provide orthotropic or even isotropic mechanical properties to the $\mathrm{FRC}^{14)}$. The employment of fibers with different orientations can change the dynamics of the adhesive interface and play a role in influencing interfacial bond failure ${ }^{11)}$. Indeed, previous studies had demonstrated the 
ability of glass fibers to withstand tensile stress and stop crack propagation in composite materials ${ }^{15,16)}$. However, only a few studies have examined the effect of FRC layer at the tooth-resin composite interface ${ }^{10,11,17,18)}$. Moreover, none of the published research has investigated the effect of silicon forming aids, which were developed for forming and positioning fibers to their right positions in clinical applications.

Based on these considerations, the purpose of this study was to investigate the effect of bidirectional FRC at the interface on bond strength of resin core system to bovine dentin by using different adhesive systems. In addition, the possible contribution of silicon forming aid to interfacial bonding was examined.

\section{MATERIALS AND METHODS}

\section{Specimen preparation}

Sixty freshly extracted bovine incisors were used as test substrates. The labial surface of each tooth was wet-ground with silicon carbide abrasive papers up to No. 320 (Federation of European Producers of Abrasives (FEPA), Paris, France) under water cooling with a grinding machine (Struers RotoPol 11, Struers A/S, Rodovre, Denmark) to create a flat dentin surface. Following which, the root of each tooth was removed with a diamond wafering blade (Ernst Leitz GMBH, Wetzlar 1600, Germany). Specimens were

Table 1 Materials used in this study

\begin{tabular}{|c|c|c|c|c|c|c|}
\hline Trade name & \multicolumn{2}{|c|}{ Type } & $\begin{array}{l}\text { Batch } \\
\text { number }\end{array}$ & Composition & Manufacturer & $\begin{array}{l}\text { Bonding } \\
\text { procedure }\end{array}$ \\
\hline \multirow[t]{2}{*}{ Solobond plus } & $\begin{array}{l}\text { Two-stage } \\
\text { universal } \\
\text { bonding agent }\end{array}$ & $\begin{array}{l}\text { Etching } \\
\text { agent } \\
\text { (Vococid) }\end{array}$ & 590722 & $36 \%$ phosphoric acid & \multirow[b]{2}{*}{$\begin{array}{l}\text { Voco GmbH, } \\
\text { Cuxhaven, } \\
\text { Germany }\end{array}$} & $\begin{array}{l}\text { Etch for } 15 \mathrm{~s}, \\
\text { rinse, dry } \\
\text { gently }\end{array}$ \\
\hline & & Adhesive & 591582 & $\begin{array}{l}\text { Water, acetone, maleic acid, } \\
\text { acid-functionalized } \\
\text { methacrylates, fluorides } \\
\text { Acetone, dimethacrylate, } \\
\text { hydroxymetahcrylate }\end{array}$ & & $\begin{array}{l}\text { Apply } \\
\text { adhesive for } \\
15 \mathrm{~s} \text {, dry and } \\
\text { light } \\
\text { polymerize for } \\
10 \mathrm{~s}\end{array}$ \\
\hline \multirow[t]{2}{*}{$\begin{array}{l}\text { Clearfil SE } \\
\text { Bond }\end{array}$} & $\begin{array}{l}\text { Self-etch two } \\
\text { bottle system }\end{array}$ & Primer & 00648A & $\begin{array}{l}\text { Water, HEMA }{ }^{\mathrm{a}}, \mathrm{MDP}^{\mathrm{b}} \text {, } \\
\text { camphorquinone, hydrophilic } \\
\text { dimethacrylate }\end{array}$ & & $\begin{array}{l}\text { Apply primer } \\
\text { for } 20 \mathrm{~s} \\
\text { gently dry }\end{array}$ \\
\hline & & Adhesive & 00920A & $\begin{array}{l}\mathrm{MDP}^{\mathrm{b}}, \text { Bis-GMA }^{\mathrm{c}}, \mathrm{HEMA}^{\mathrm{a}}, \mathrm{N}, \\
\text { N-diethanol-p-toluidine, } \\
\text { hydrophobic dimethacrylate, } \\
\text { silanated colloidal silica }\end{array}$ & $\begin{array}{l}\text { Kuraray Co. } \\
\text { Ltd, Osaka, } \\
\text { Japan }\end{array}$ & $\begin{array}{l}\text { Apply } \\
\text { adhesive for } \\
15 \mathrm{~s} \text {, dry for } \\
5 \mathrm{~s} \text { and light } \\
\text { polymerize } \\
\text { for } 10 \mathrm{~s}\end{array}$ \\
\hline $\begin{array}{l}\text { Clearfil DC } \\
\text { Core Automix }\end{array}$ & \multicolumn{2}{|c|}{$\begin{array}{l}\text { Dual-cured core } \\
\text { build-up material }\end{array}$} & $00027 \mathrm{~A}$ & $\begin{array}{l}\text { Bis-GMA }, \mathrm{MDP}^{\mathrm{b}} \text {, } \\
\text { dimethacrylate, filler, } \\
\text { photo/chemical initiotor }\end{array}$ & $\begin{array}{l}\text { Kuraray Co. } \\
\text { Ltd, Osaka, } \\
\text { Japan }\end{array}$ & \\
\hline Stick-Net & \multicolumn{2}{|c|}{ Glass fiber weave } & $\begin{array}{l}2050712 \\
-\mathrm{w}-0054\end{array}$ & $\begin{array}{l}\text { Porous PMMA }{ }^{\mathrm{d}} \text { impregnated } \\
\text { bidirectional E-glass fibers }\end{array}$ & $\begin{array}{l}\text { Stick Tech, } \\
\text { Turku, Finland }\end{array}$ & \\
\hline Stick resin & \multicolumn{2}{|c|}{ Light curing resin } & 5504765 & Bis-GMA $^{c}$ - TEGDMA ${ }^{\mathrm{e}}$ & $\begin{array}{l}\text { Stick Tech, } \\
\text { Turku, Finland }\end{array}$ & \\
\hline
\end{tabular}

aHEMA, hydroxyethyl methacrylate; ${ }^{\mathrm{b}} \mathrm{MDP}, 10$-methacryloyloxydecyl dihydrogen phosphate; ${ }^{\mathrm{c}}$ Bis-GMA, bisphenol

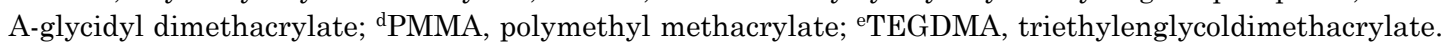




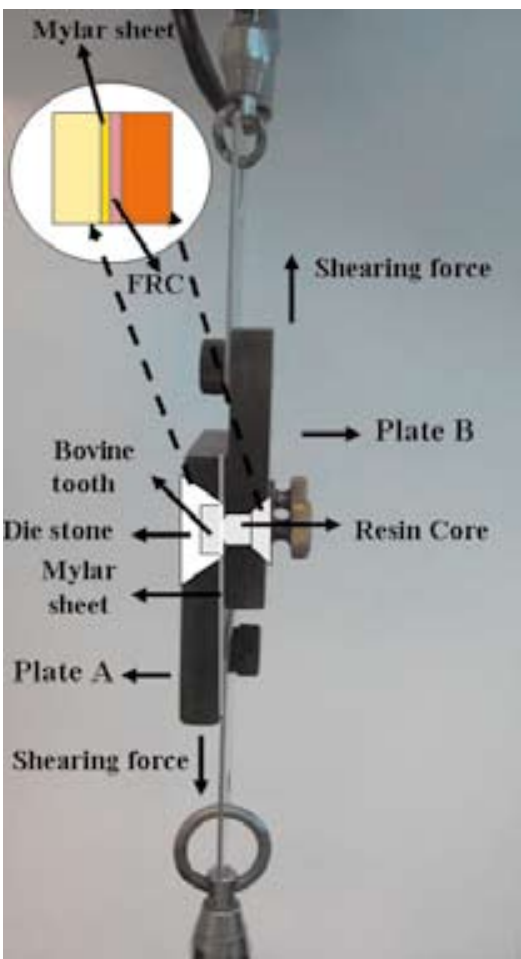

Fig. 1 Single plane shear test assembly.

maintained in a fully hydrated state throughout the entire preparation procedure.

A Mylar strip (DuPont Corp., Wilmington, USA) with a 3-mm-diameter hole was centered on the dentin surface to standardize the exposed area, and then burnished on the dentin surface to ensure tight adhesion to the specimen. Finally, the specimens were mounted in the countersunk hole in plate A of the shearing apparatus (Fig. 1) using a die stone (Fuji Rock, GC, Tokyo, Japan).

\section{Bonding procedures}

The prepared teeth were divided into two groups: total-etching versus self-etching. Each group was further divided into two sub-groups: with or without FRC (control group). FRC groups were in turn subdivided into two more groups: presence or absence of silicon forming aid to FRC layer to the dentin surface.

Following complete set of the die stone, the dentin surfaces were treated with the materials listed in Table 1 according to manufacturers' instructions. In FRC groups, after primer application on dentin, the adhesive resin of FRC (Stick Resin, StickTech, Turku, Finland) was applied together with one layer of bidirectional, light-polymerizable, polymer-impregnated E-glass fibers (Stick Net, StickTech) of $3 \mathrm{~mm}$ diameter. For FRC groups to be examined for the effect of silicon forming aid, the fibers were adapted to the tooth surface with a transparent silicon device (Refix D, StickTech). Then, for all FRC groups with or without silicon forming aid, they were light-polymerized for 10 seconds with a quartz-tungsten-halogen (QTH) unit (Optilux 501, Kerr, Danbury, CA, USA) under continuous mode. To improve the adhesion of resin core to the polymer-impregnated fibers, the fiber layers were treated with an adhesive resin (Stick Resin, StickTech) for 24 hours prior to their application. Finally, the resin core system (Clearfil DC Core, Kuraray Co. Ltd.) was condensed into the countersunk hole in plate B (Fig. 1) and polymerized for 40 seconds with a QTH unit (Optilux 501, Kerr).

\section{Shear bond test}

After 24 -hour storage in $100 \%$ humidity at $37^{\circ} \mathrm{C}$, the test specimens were mounted into the single plane shear test assembly, aligning the abrasion marks to shear direction. The screws securing plate A to plate $B$ were removed just before loading, and then shearing force was applied at a crosshead speed of 1 $\mathrm{mm} / \mathrm{min}$ using a universal testing machine (Lloyd LRX, Lloyd Instruments Ltd., Fareham Hants, UK) until failure occurred. Shear bond strength was calculated by dividing the maximum load at failure (N) with the bonding area $\left(\mathrm{mm}^{2}\right)$ and recorded in megapascals $(\mathrm{MPa})$.

Failure modes were examined visually with an optical microscope at $\times 40$ magnification (Stereomicroscope; Wild M3B, Heerbrugg, Switzerland). Two specimens representative of the fracture mode from each group were prepared for scanning electron microscope (SEM) analysis. The specimens were sputter-coated (Bal-Tec SCD 050 Sputter Coater, Bal-Tec AG, Liechtenstein) with gold and observed with a SEM (JSM-5500, JEOL Ltd., Tokyo, Japan). Furthermore, one specimen from each adhesive system was stored in $2 \mathrm{M}$ hydrochloric acid $(\mathrm{HCl})$ for 48 hours to demineralize the tooth structure and reveal the resin tag formation ${ }^{19)}$. After being extensively rinsed, specimens were freeze-dried ${ }^{20)}$, gold sputter-coated, and then observed with a SEM (JSM-5500).

\section{Statistical evaluation}

Shear bond strength (SBS) data were analyzed statistically by three-factor analysis of variance (ANOVA) and Tukey's post hoc test, with the level of significance set at $\mathrm{p}<0.05$. All statistical analyses were performed using a statistical software package (SPSS Inc., Chicago, IL, USA).

\section{RESULTS}

Figure 2 summarizes the mean SBS values and standard deviations of the test groups. Three-way ANOVA (Table 2) indicated a significant effect of the 
presence of FRC at the interface on SBS $(p<0.001)$. However, the effects of adhesive system $(p=0.076)$ and the silicon forming aid $(p=0.348)$ were not statistically significant. The highest mean SBS value was seen in Group TFP $(19.3 \pm 2.4 \mathrm{MPa})$ and the lowest in Group SC (11.1 $\pm 1.7 \mathrm{MPa})$.

Table 3 shows the distribution of failure modes of the test groups. In the control groups (Group TC and SC), it was solely adhesive failure between dentin and the resin core. In groups that had an FRC layer adapted with silicon forming aid, failures were mostly cohesive within the FRC layer (Group TFP: 80\%; Group SFP: 70\%). However, in groups without silicon forming aid, failures were predominantly adhesive between dentin and resin core (Group TFW: 30\%; Group SFW: 30\%) and cohesive within the FRC layer (Group TFW: 60\%; Group SFW: 50\%).

Figure 3 shows the stereomicroscopic images of cohesive failure within the FRC layer. SEM micrographs of adhesive failure at the dentin-resin core interface, cohesive failure within the FRC layer, and mixed failure are shown in Fig. 4. SEM photomicrographs after removal of tooth structure are shown in Fig. 5.

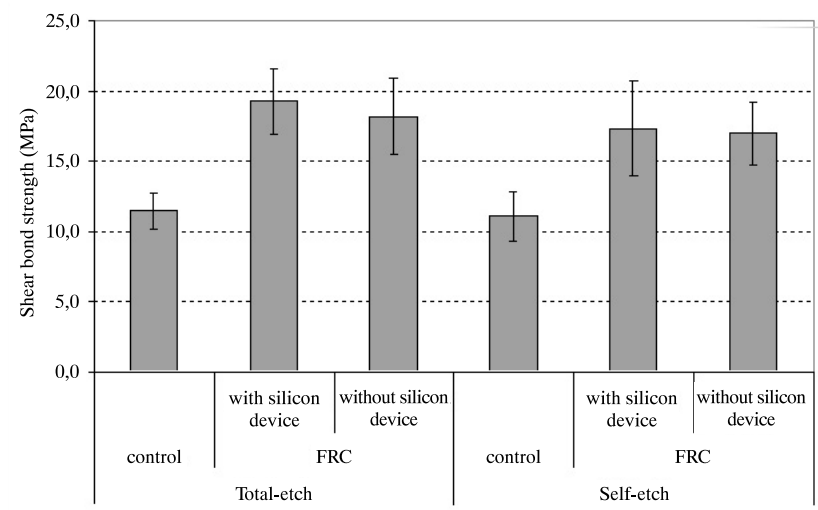

Fig. 2 Shear bond strength $(\mathrm{MPa})$ values of resin core system to bovine dentin.

Table 2 Analysis of variance of shear bond strength results

\begin{tabular}{|c|c|c|c|c|c|}
\hline Source variation & $d f$ & Sum of squares & Mean square & $\mathrm{F}$ & $P$ \\
\hline Corrected model & 5 & $628.493^{\mathrm{a}}$ & 125.699 & 21.961 & .000 \\
\hline Intercept & 1 & 13065.250 & 13065.250 & 2282.664 & .000 \\
\hline Adhesive system & 1 & 18.766 & 18.766 & 3.279 & .076 \\
\hline FRC & 1 & 401.259 & 401.259 & 70.105 & .000 \\
\hline Silicon device & 1 & 5.119 & 5.119 & .894 & .348 \\
\hline Adhesive system X FRC & 1 & 1.548 & 1.548 & .271 & .605 \\
\hline Adhesive system X Silicon device & 1 & 1.380 & 1.380 & .241 & .625 \\
\hline FRC X Silicon device & 0 & .000 & & & \\
\hline Adhesive system X FRC X Silicon device & 0 & .000 & & & \\
\hline Error & 54 & 309.079 & 5.724 & & \\
\hline Total & 60 & 15745.818 & & & \\
\hline Correceted total & 59 & 937.572 & & & \\
\hline
\end{tabular}

a. $\mathrm{R}$ Squared $=.670$ (Adjusted $\mathrm{R}$ Squared $=.640)$

Table 3 Failure mode analysis of the test groups $(n=10)$

\begin{tabular}{|c|c|c|c|c|c|}
\hline \multicolumn{2}{|c|}{ Group name } & \multicolumn{2}{|r|}{$\begin{array}{c}\text { Adhesive between } \\
\text { resin-core and } \\
\text { dentin }\end{array}$} & Cohesive in FRC & Mixed \\
\hline \multirow{3}{*}{ Total-etch } & control & $\mathrm{TC}$ & $10(100 \%)$ & 0 & 0 \\
\hline & FRC with silicon device & TFP & $1(10 \%)$ & $8(80 \%)$ & $1(10 \%)$ \\
\hline & FRC without silicon device & TFW & $3(30 \%)$ & $6(60 \%)$ & $1(10 \%)$ \\
\hline \multirow{3}{*}{ Self-etch } & control & $\mathrm{SC}$ & $10(100 \%)$ & 0 & 0 \\
\hline & FRC with silicon device & SFP & $1(10 \%)$ & $7(70 \%)$ & $2(20 \%)$ \\
\hline & FRC without silicon device & SFW & $3(30 \%)$ & $5(50 \%)$ & $2(20 \%)$ \\
\hline
\end{tabular}



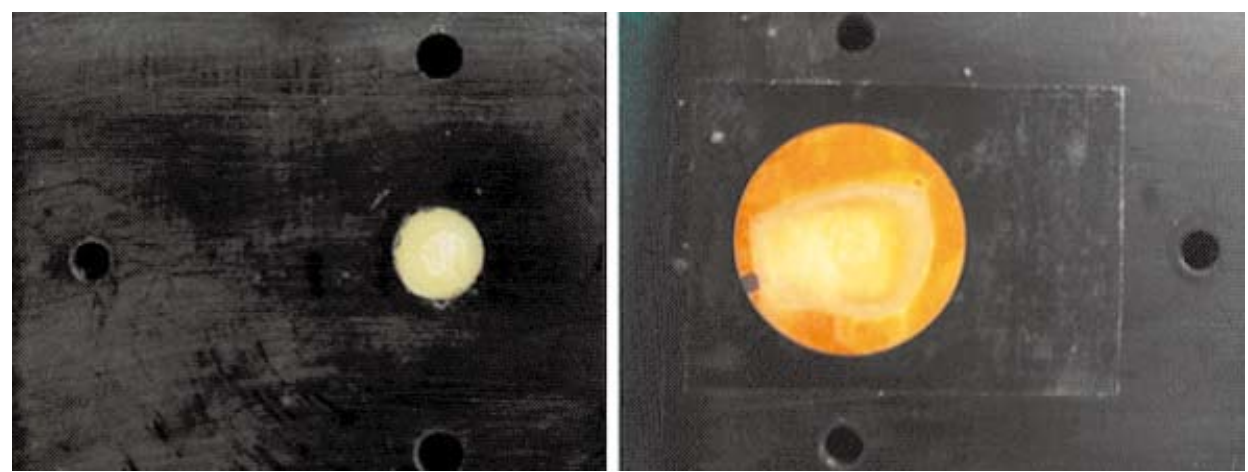

Fig. 3 Fractured surfaces of dentin and resin core material showing cohesive failure in FRC.

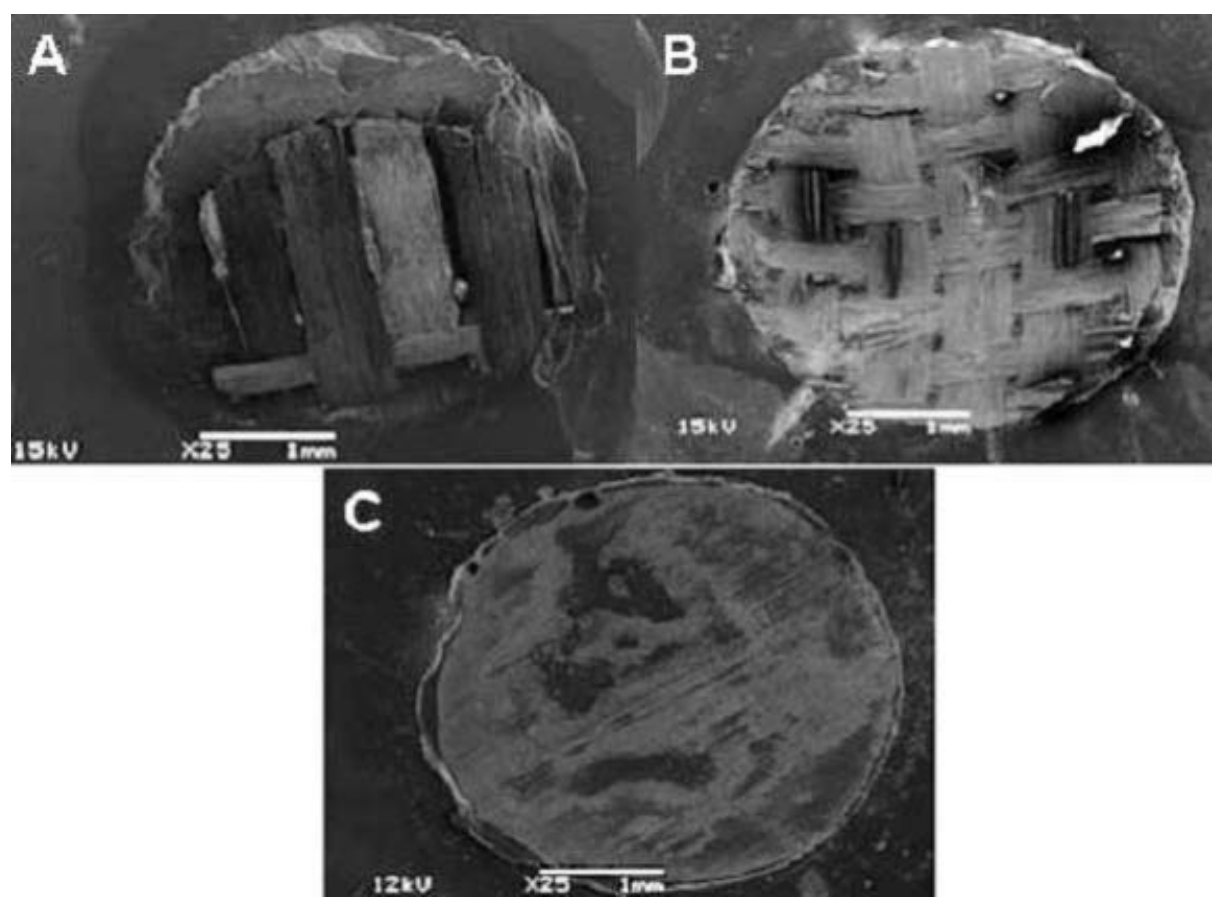

Fig. 4 SEM micrographs of fracture surfaces. A: Mixed failure in Group SFP; B: Cohesive failure in FRC in Group TFP; $\mathrm{C}$ : Adhesive failure between resin core and dentin. Original magnification $\times 25$, bar $=1 \mathrm{~mm}$.

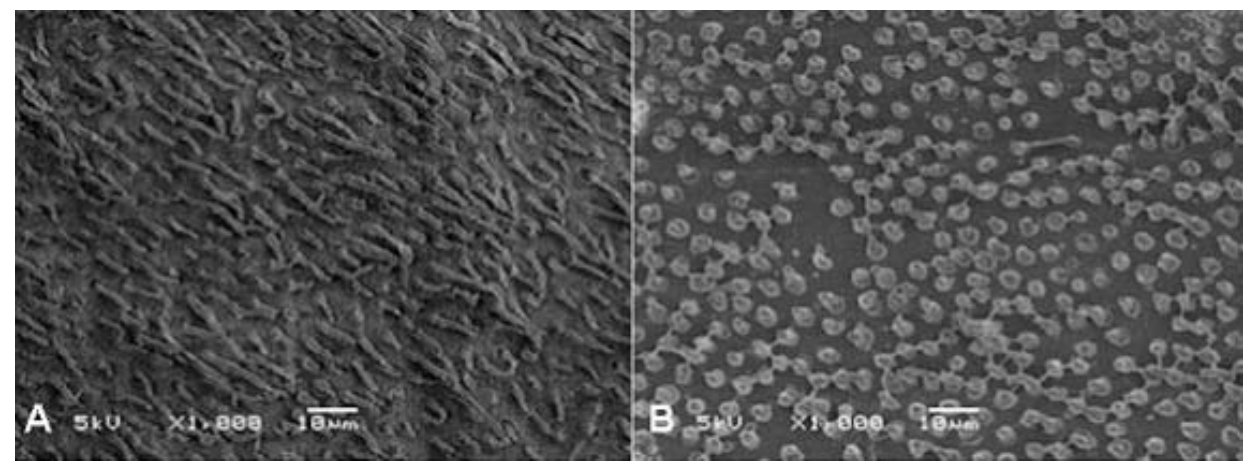

Fig. 5 SEM photomicrographs of the resin tag formation after dissolving tooth structure with 2 M HCl. Resin replica of the dentin surface with: (A) Solobond Plus adhesive system, where a regular distribution could be observed with numerous, longer resin tags; and (B) Clearfil SE Bond, where a non-uniform distribution of shorter and thinner resin tags extending longitudinally to the dentin wall could be observed. Original magnification $\times 1000$, bar $=10 \mu \mathrm{m}$. 


\section{DISCUSSION}

Amid the diverse spectrum of bond strength testing methods, shear bond testing has become very popular ${ }^{9,11,21)}$. This is chiefly because shear stress is believed to be the major stress which accounts for the bond failures of restorative materials in vivo ${ }^{22}$. Several testing configurations have been used including loops, points, and knife edges - to apply shear force. However, a major problem with these methods lies in the difficulty of placing the shear loading device in close alignment with the bond interface $^{23)}$. As for the single plane shear test assembly used in this study, the shear loading device was positioned in line with the bond interface zone and applied the stress through this zone in a specific plane $^{22)}$. This design supported the restorative material and that there was no point contact during load application ${ }^{24)}$.

The mean shear bond strength values found in this study were lower than those in previous studies $^{8,25)}$. Giannini et al. used the wire loop technique in a study and reported a mean bond strength of $37.06 \pm 4.88 \mathrm{MPa}$ for Clearfil DC Core with Clearfil SE Bond ${ }^{25)}$. However, in the present study, the mean bond strength for this combination was found to be $11.1 \pm 1.7 \mathrm{MPa}$. On the other hand, another study - which employed a knife-edge shear test method - showed a more similar shear bond strength value for Clearfil DC Core with Clearfil PhotoBond $(14.6 \pm 2.4 \mathrm{MPa})^{8)}$. Put together, these aforementioned variations could be attributed to one or a combination of causes arising from bonding methodology, storage environment, and testing techniques.

The silicon forming aid investigated in this study is currently used by dentists for better positioning of the FRC layer, as suggested by the manufacturer. In view of this recommendation, it was hypothesized in this study that the application of FRC to the dentinresin core interface with the use of silicon forming aid would increase the bond strength. Based on the results obtained, this hypothesis was partially accepted in both FRC test groups. It must be clarified that whereas the FRC significantly increased the bond strength, the silicon forming aid did not lead to a significant increase in bond strength.

The addition of FRC improved the shear bond strength as the layer thus created acted as an impediment to crack formation and debonding. As for the bonding ability of FRC to the characteristics of adhesive resins to the tooth surface and $\mathrm{FRC}^{26}$. In the current study, the bidirectional FRC used probably mimicked the biomechanics of tooth structure and hence increased the bonding surface area of dentin. Furthermore, the continuous fibers could transfer stress to a wider surface area, thereby diminishing stress - and hence the possibility of debonding - at the interface ${ }^{17}$.

Previous studies have reported that HEMAcontaining resins or methyl methacrylate monomer in combination with some dimethacrylate monomer systems can promote the diffusion of the monomer and to some extent dissolve the linear polymer phase of the FRC on the bonding surface ${ }^{27,28)}$. On this note, the positive effect of FRC on bond strength could be related with the adhesive systems used in this study. Clearfil SE and Solobond Plus contained HEMA and some dimethacrylate monomers respectively. The preimpregnation of FRC using a light-polymerizable resin system formed a semi-interpenetrating polymer network (semi-IPN) after being polymerized. The FRC with a semi-IPN matrix then adhered with the resin composite by means of interdiffusion bonding ${ }^{11}$. Consequently, the results of the present study were in good agreement with studies that showed good adhesion between the adhesive resin and $\mathrm{FRC}^{26-28)}$.

To date, few studies have investigated the effect of thermocycling on the stability of bonding layers with FRC. These studies have yielded encouraging results with slight increase in bond strength values $^{11,28)}$. Nevertheless, although FRC seemingly has a positive effect on bond durability in clinical practice, its long-term stability needs further investigation.

In the present study, the bond failures of all the control groups (TC and SC) occurred adhesively between the resin core and dentin (Fig. 4C). In the FRC groups with silicon forming aid, failures were predominantly cohesive within FRC (TFP: 80\%; SFP: 70\%) (Fig. 4B). It was observed that the number of cohesive failures within FRC tended to increase as higher shear bond strength values were yielded. Results of this study were in accordance with previous studies which showed changes in fracture pattern owing to the addition of FRC to the interface ${ }^{14,17,18)}$. Fennis et al. investigated the effect of FRC on the fracture resistance of cusp-replacing composite restorations, whereby it was concluded that glass FRCs had a beneficial effect on the failure mode and thereby on re-restorability in the event of a fracture ${ }^{18)}$. In FRC groups with silicon forming aid (TFP, SFP), the adhesive failure percentage was $10 \%$ whereas it was $30 \%$ in FRC groups without silicon forming aid (TFW, SFW). The increase in adhesive failure percentage could be related to the inadequate adaptation of FRC to the tooth surface.

Previous studies have investigated the effectiveness of self-etching adhesive systems and their adhesion to both dentin and enamel, but controversial results were yielded regarding the bonding performance of these systems ${ }^{6,13,14,21,29,30)}$. Clearfil SE Primer, used in this study, is considered as a mild acidic agent with a $\mathrm{pH}$ of 2.0. Mild self-etch 
adhesives produce hybrid layers thinner than totaletch systems ${ }^{7}$. In this study, the SEM images of specimens prepared from the adhesive systems showed difference in surface texture between the two systems. Solobond Plus adhesive system yielded a uniform formation of numerous resin tags that were longer in length. With Clearfil SE Bond, a nonuniform formation of shorter resin tags was obtained (Fig. 5). These findings were consistent with those of previous studies, which reported that resin tags made only a minor contribution to bond strength ${ }^{7,31,32}$. As a result, the shear bond strengths obtained with Clearfil SE Bond were statistically similar $(p=0.076)$ to those obtained with Solobond Plus in this study.

The comparable bonding performance of Clearfil SE Bond could be attributed to the synergy of an unsaturated methacrylate phosphate ester (10-MDP) as the acidic monomer in combination with hydroxyethyl methacrylate (HEMA), which is believed to improve wetting of the tooth surface and chelate to calcium ions of dentin ${ }^{33}$. Additionally, adhesive strength might be governed by mechanical interlocking with hydroxyl apatite crystals within the hybrid layer, thereby resulting in a more rigid and compact interface ${ }^{34)}$. In a review by Peumans et al., two-step self-etch adhesives have been shown to approach the gold standard of three-step total-etch adhesive systems in terms of clinical bonding effectiveness $^{35}$. Therefore, these simplified adhesives wield numerous clinical advantages: faster and easier to use, and reduced technique sensitivity. Nonetheless, long-term clinical studies are still required to further understand the bonding interface produced by self-etching systems.

Although bovine and human teeth have different features especially in terms of morphology, several studies have demonstrated similarities between these two types of substrates. In bonding tests, similar results were reported between bovine and human dentin as well as in the number and distribution of dentinal tubules ${ }^{36,37)}$. In this study, bovine dentin was chosen as the substrate because of the convenient size of the teeth. Moreover, the use of bovine teeth facilitates the ease of obtaining uniform surfaces for bonding, which are suitable for primary screening tests ${ }^{38}$. It has been demonstrated that bovine teeth are a good substitute for human teeth, although slightly lower values are frequently obtained $^{39}$. It is therefore noteworthy that all these non-standardized parameters in bond strength studies make it difficult to compare results of different studies.

\section{CONCLUSIONS}

Within the limitations of this in vitro study, the following conclusions were drawn:
(1) Addition of an FRC layer did significantly improve the shear bond strength of resin core to bovine dentin. However, use of silicon forming aid did not result in significant improvement of bond strength.

(2) Solobond Plus (three-step total-etching system) and Clearfil SE Bond (two-step self-etching system) provided equally effective bond strengths to bovine dentin.

\section{ACKNOWLEDGEMENTS}

This study was financed by a fund from the Scientific Research Projects Unit of Gazi University and in part by a contribution from the Bio and Nanopolymers Research Group, Center of Excellence of the Academy of Finland.

\section{REFERENCES}

1) Belli S, Cobankara FK, Eraslan O, Eskitascioglu G, Karbhari V. The effect of fiber insertion on fracture resistance of endodontically treated molars with MOD cavity and reattached fractured lingual cusps. J Biomed Mater Res Part B Appl Biomater 2006; 79: $35-41$.

2) Stober T, Rammelsberg P. The failure rate of adhesively retained composite core build-ups in comparison with metal-added glass ionomer core build-ups. J Dent 2005; 33: 27-32.

3) Oooka S, Miyazaki M, Takamizawa T, Tsubota K, Kurokawa H, Rikuta A. Influence of adhesive polymerization mode on dentin bond strength of direct core foundation systems. J Oral Sci 2004; 46: 185-189.

4) Caughman WF, Chan DC, Rueggeberg FA. Curing potential of dual-polymerizable resin cements in simulated clinical situations. J Prosthet Dent 2001; 86: 101-106.

5) Breschi L, Mazzoni A, Ruggeri A, Cadenaro M, Di Lenarda R, De Stefano Dorigo E. Dental adhesion review: Aging and stability of the bonded interface. Dent Mater 2008; 24: 90-101.

6) Omar H, El-Badrawy W, El-Mowafy O, Atta O, Saleem B. Microtensile bond strength of resin composite bonded to caries-affected dentin with three adhesives. Oper Dent 2007; 32: 24-30.

7) Deliperi S, Bardwell DN, Wegley C. Restoration interface microleakage using one total-etch and three self-etch adhesives. Oper Dent 2007; 32: 179184.

8) Oooka S, Miyazaki M, Rikuta A, Moore K. Influence of polymerization mode of dual-polymerized resin direct core foundation systems on bond strengths to bovine dentin. J Prosthet Dent 2004; 92: 239-244.

9) McDonough WG, Antonucci JM, Dunkers JP. Interfacial shear strengths of dental resin-glass fibers by the microbond test. Dent Mater 2001; 17: 492-498.

10) Meiers JC, Kazemi RB, Donadio M. The influence of fiber reinforcement of composites on shear bond 
strengths to enamel. J Prosthet Dent 2003; 89: 388393.

11) Tezvergil A, Lassila LVJ, Vallittu PK. The shear bond strength of bidirectional and random-oriented fiber-reinforced composite to tooth structure. J Dent 2005; 33: 509-516.

12) Vallittu PK. Use of woven glass fibres to reinforce a composite veneer. A fracture resistance and acoustic emission study. J Oral Rehabil 2002; 29: 423-429.

13) Ergun G, Cekic I, Lassila LV, Vallittu PK. Bonding of lithium-disilicate ceramic to enamel and dentin using orthotropic fiber-reinforced composite at the interface. Acta Odontol Scand 2006; 64: 293-299.

14) Cekic I, Ergun G, Uctasli S, Lassila LV. In vitro evaluation of push-out bond strength of direct ceramic inlays to tooth surface with fiber-reinforced composite at the interface. J Prosthet Dent 2007; 97: 271-278.

15) Vallittu PK. Flexural properties of acrylic resin polymers reinforced with unidirectional and woven glass fibers. J Prosthet Dent 1999; 81: 318-326.

16) Lassila LVJ, Nohrström T, Vallittu PK. The influence of short-term water storage on the flexural properties of unidirectional glass fiber-reinforced composites. Biomaterials 2002; 23: 2221-2229.

17) Tezvergil A, Lassila LVJ, Vallittu PK. Strength of adhesive bonded fiber reinforced composites to enamel and dentin substrates. J Adhes Dent 2003; 4: 301-311.

18) Fennis WM, Tezvergil A, Kuijs RH, Lassila LV, Kreulen CM, Creugers NH, Vallittu PK. In vitro fracture resistance of fiber reinforced cusp-replacing composite restorations. Dent Mater 2005; 21: 565572.

19) Giachetti L, Bertini F, Scaminaci Russo D. Investigation into the nature of dentin resin tags: a scanning electron microscopic morphological analysis of demineralized bonded dentin. J Prosthet Dent 2004; 92: 233-238.

20) Sanchez-Quevedo MC, Nieto-Albano OH, Garcia JM, Gomez de Ferraris ME, Campos A. Electron probe microanalysis of permanent human enamel and dentine. A methodological and quantitative study. Histol Histopathol 1998; 13: 109-113.

21) Swift EJ Jr, Perdigao J, Heymann HO. Bonding to enamel and dentin: a brief history and state of the art. Quintessence Int 1995; 26: 95-110.

22) Watanabe LG, Marshall GW, Marshall SJ. Variables influence on shear bond strength testing to dentin. In: Advanced adhesive dentistry, Tagami J, Toledano M, Prati C (eds.), 3rd International Kuraray Symposium, Kuraray Co. Ltd., Cirimido, Italy, 1999, pp. $75-90$.

23) Watanabe LG, Marshall GW Jr, Marshall SJ. Dentin shear strength: effects of tubule orientation and intratooth location. Dent Mater 1996; 12: 109. 115 .

24) Schneider BT, Baumann MA, Watanabe LG, Marshall GW Jr. Dentin shear bond strength of compomers and composites. Dent Mater 2000; 16:
15-19.

25) Giannini M, De Goes MF, Nikaido T, Shimada Y, Tagami J. Influence of activation mode of dual-cured resin composite cores and low-viscosity composite liners on bond strength to dentin treated with selfetching adhesives. J Adhes Dent 2004; 6: 301-306.

26) Meiers JC, Duncan JP, Freilich MA, Goldberg AJ. Preimpregnated, fiber-reinforced prostheses. Part II. Direct applications: splints and fixed partial dentures. Quintessence Int 1998; 29: 761-768.

27) Lastumäki TM, Kallio TT, Vallittu PK. The bond strength of light-curing composite resin to finally polymerized and aged glass fiber-reinforced composite substrate. Biomaterials 2002; 23: 45334539.

28) Kallio TT, Lastumäki TM, Vallittu PK. Bonding of restorative and veneering composite resin to some polymeric composites. Dent Mater 2001; 17: 80-86.

29) Ishikawa A, Shimada Y, Foxton RM, Tagami J. Micro-tensile and micro-shear bond strengths of current self-etch adhesives to enamel and dentin. Am J Dent 2007; 20: 161-166.

30) Cekic I, Ergun G, Lassila LV, Vallittu PK. Ceramicdentin bonding: effect of adhesive systems and lightcuring units. J Adhes Dent 2007; 9: 17-23.

31) Loguercio AD, Reis A, Bortoli G, Patzlaft R, Kenshima S, Rodrigues Filho LE, Accorinte Mde L, van Dijken JW. Influence of adhesive systems on interfacial dentin gap formation in vitro. Oper Dent 2006; 31: 431-441.

32) Tao L, Pashley DH. Shear bond strengths to dentin: effects of surface treatments, depth and position. Dent Mater 1988; 4: 371-378.

33) Proenca JP, Polido M, Osorio E, Erhardt MC, Aguilera FS, Garcia-Godoy F, Osorio R, Toledano M. Dentin regional bond strength of self-etch and totaletch adhesive systems. Dent Mater 2007; 23: 15421548.

34) Kaaden C, Powers JM, Friedl KH, Schmalz G. Bond strength of self-etching adhesives to dental hard tissues. Clin Oral Investig 2002; 6: 155-160.

35) Peumans M, Kanumilli P, De Munck J, Van Landuyt K, Lambrechts P, Van Meerbeek B. Clinical effectiveness of contemporary adhesives: A systematic review of current clinical trials. Dent Mater 2005; 21: 864-881.

36) Saunders WP. The shear impact retentive strengths of four dentine bonding agents to human and bovine dentine. J Dent 1988; 16: 233-238.

37) Ruse ND, Smith DC. Adhesion to bovine dentin - surface characterization. J Dent Res 1991; 70: 1002-1008.

38) Kitasako Y, Burrow MF, Nikaido T, Tagami J. The influence of storage solution on dentin bond durability of resin cement. Dent Mater 2000; 16: 16.

39) Phrukkanon S, Burrow MF, Hartley PG, Tyas MJ. The influence of the modification of etched bovine dentin on bond strengths. Dent Mater 2000; 16 : $255-265$. 